\title{
Paleoanthropology: Two New Offerings
}

\author{
How Humans Evolved, 5th Ed., by Robert Boyd and Joan Silk. New York: W. W. Norton, \\ 2009. pp 474 + front and end matter. $P / b \$ 119.75$
}

\author{
Sexual Selection and the Origin of Human Mating Systems, by Alan F. Dixson. Oxford, \\ 2009. UK: Oxford University Press. Pp 232. P/b $\$ 70.00$
}

\section{Ian Tattersall}

Published online: 10 August 2010

(C) Springer Science+Business Media, LLC 2010

As the primatological and paleoanthropological literatures continue to proliferate at a rate far above what any sensate individual can reasonably be expected to absorb, succinct overviews of individual fields are increasingly welcome. Just such an overview, of the field of higher primate reproductive behavior, is what Alan Dixson provides in his new volume on Sexual Selection and the Origin of Human Mating Systems - although, as his title suggests, he provides it from a very specific and clearly articulated standpoint, and the whole enterprise is ultimately aimed at "explor[ing] the evolutionary origins of human mating systems, the physical determinants of sexual attractiveness, mate choice, and patterns of copulatory behavior" (p. 1).

Dixson approaches this goal by stringing together a series of essays, each one more or less self-contained, but all quite seamlessly linked into a continuous narrative. As he himself notes, "given that sexual behaviour does not leave a fossil record" (p. 1) his self-imposed task is not an easy one; but his attempt is highly readable at the very least. The book starts with the obligatory canter through human phylogeny, in which most presumed sexual differences observed among fossils are attributed to "intrasexual selection." The selectionist tone established here continues throughout the next several chapters. These are devoted to testis size and social organization; sperm morphology and competition and penis morphology; female choice, orgasm, and reproductive tracts; copulatory positions and patterns; the general lack of true estrus

I. Tattersall $(\bowtie)$

Division of Anthropology, American Museum of Natural History,

New York, NY 10024, USA

e-mail: iant@amnh.org among higher primates and the fallacy of its "loss" in human evolution; human sexual dimorphism and its correlates; and the specific issue of sexual dimorphism in human laryngeal structure and its relation to a putatively polygynous ancestral social organization.

The final summary chapter ranges widely in support of the uneasily-paired notions that "Homo sapiens evolved from a primarily polygynous non-human primate precursor" (p. 180) and that "the propensity for men and women to form long-lasting relationships for reproductive purposes is an ancient trait, probably present in the earliest members of the genus Homo" (p. 180). Along the way, Dixson warns that we should not let our cognitive sophistication obscure the fact that our behaviors are often driven by some pretty atavistic influences; he dismisses sperm competition and related theories about female orgasm as major influences in the evolution of the human reproductive system; he expresses doubt that there's anything particularly special about human copulatory postures or patterns; and he cogitates on much more besides. But simply summarizing its chapters hardly does justice to a book that is crammed with interesting and often obscure facts, lively speculations, and measured judgments on some of the more extravagant sociobiological claims about human reproductive behaviors. Particularly because of its highly selectionist stance, the book is a very useful antidote to the typical enthusiasm of the Press for such claims. So if you're interested in human evolution, read this book. For all that it will probably have you grinding your teeth in places, it treads important ground that members of our prudish species often prefer to ignore, and there is nothing else out there quite like it.

While Dixson's book is written for graduate students and colleagues, Boyd and Silk's How Humans Evolved is the 
latest version of a successful undergraduate text. This fifth edition is a polished production that ranges over the obligatory territory: adaptation and natural selection; genetics; evolutionary patterns and speciation; phylogeny reconstruction; primate ecology and behavior (with a substantial nod to reproductive and mating systems and a decent dollop of sociobiology); primate and human evolution; modern human genetic variation; and back to the evolutionary underpinnings of human behavior. Each area gets its adequate due, but this is very clearly a book that is written by a cultural specialist and a primatologist, to be used by those teaching human evolution from the primatological and cultural perspectives. For hard-core paleoanthropologists, there are better alternatives out there, as there are for teachers who wish to steer away from the Siren attractions of evolutionary psychology. 